\title{
Retinopathy of Prematurity
}

National Cancer Institute

\section{Source}

National Cancer Institute. Retinopathy of Prematurity. NCI Thesaurus. Code C34982.

A bilateral retinopathy characterized by neovascularization, scarring, retinal detachment, and eventually blindness. It may be mild or severe. It occurs in babies born prematurely. Causes include oxygen toxicity and hypoxia. 